\title{
HIGH SPATIAL RESOLUTION IMAGING OF INERTIAL FUSION TARGET PLASMAS USING BUBBLE NEUTRON DETECTORS
}

\author{
FINAL REPORT FOR THE PERIOD \\ NOVEMBER 1, 1999 THROUGH FEBRUARY 28, 2001 \\ by \\ R.K. FISHER
}

\begin{abstract}
Work prepared under
Department of Energy Grant

No. DE-FG03-00SF22019 and

Contract No. W-7405-ENG-48
\end{abstract}

JUNE 2003 


\section{DISCLAIMER}

This report was prepared as an account of work sponsored by an agency of the United States Government. Neither the United States Government nor any agency thereof, nor any of their employees, makes any warranty, express or implied, or assumes any legal liability or responsibility for the accuracy, completeness, or usefulness of any information, apparatus, product, or process disclosed, or represents that its use would not infringe privately owned rights. Reference herein to any specific commercial product, process, or service by trade name, trademark, manufacturer, or otherwise, does not necessarily constitute or imply its endorsement, recommendation, or favoring by the United States Government or any agency thereof. The views and opinions of authors expressed herein do not necessarily state or reflect those of the United States Government or any agency thereof. 


\title{
HIGH SPATIAL RESOLUTION IMAGING OF INERTIAL FUSION TARGET PLASMAS USING BUBBLE NEUTRON DETECTORS
}

FINAL REPORT FOR THE PERIOD NOVEMBER 1, 1999 THROUGH FEBRUARY 28, 2001

\author{
by \\ R.K. FISHER
}

\begin{abstract}
Work prepared under Department of Energy Grant No. DE-FG03-00SF22019 and Contract No. W-7405-ENG-48
\end{abstract}




\section{HIGH SPATIAL RESOLUTION IMAGING OF INERTIAL FUSION TARGET PLASMAS USING BUBBLE NEUTRON DETECTORS}

\section{Principal Investigator: Raymond K. Fisher in collaboration with University of Rochester, Laboratory for Laser Energetics; Association Euratom-CEA; and Lawrence Livermore National Laboratory}

Bubble detectors, which can detect neutrons with a spatial 5 to $30 \mu$, are the most promising approach to imaging NIF target plasmas with the desired $5 \mu$ spatial resolution in the target plane. Gel bubble detectors are being tested to record neutron images of ICF implosions in OMEGA experiments. By improving the noise reduction techniques used in analyzing the data taken in June 2000 , we have been able to image the neutron emission from $6 \cdot 10^{13}$ yield DT target plasmas with a target plane spatial resolution of $\sim 140 \mu$, as shown in Fig. 1. As expected, the spatial resolution was limited by counting statistics as a result of the low neutron detection efficiency of the easy-to-use gel bubble detectors. The results have been submitted for publication and will be the subject of an invited talk at the October 2001 Meeting of the Division of Plasma Physics of the American Physical Society.

To improve the counting statistics, data was taken in May 2001 using a stack of four gel detectors and integrated over a series of up to seven high-yield DT shots. Analysis of the 2001 data is still in its early stages. Gel detectors were chosen for these initial tests since the bubbles can be photographed several hours after the neutron exposure. They consist of $\sim 5000$ drops $(\sim 100 \mu$ in diameter) of bubble detector liquid $/ \mathrm{cm}^{3}$ suspended in an inactive support gel that occupies $~ 99 \%$ of the detector volume. Using a liquid bubble chamber detector and a light scattering system to record the bubble locations a few microseconds after the neutron exposure when the bubbles are $\sim 10 \mu$ in diameter, should result in $\sim 1000$ times higher neutron detection efficiency and a target plane resolution on OMEGA of $\sim 10$ to $50 \mu$.

This is a report of research performed at the National Laser Users Facility of the University of Rochester Laboratory for Laser Energetics and supported by the U.S. Department of Energy under Grant No. DE-FG03-00SF22019 and Contract No. W-7405-ENG-48.
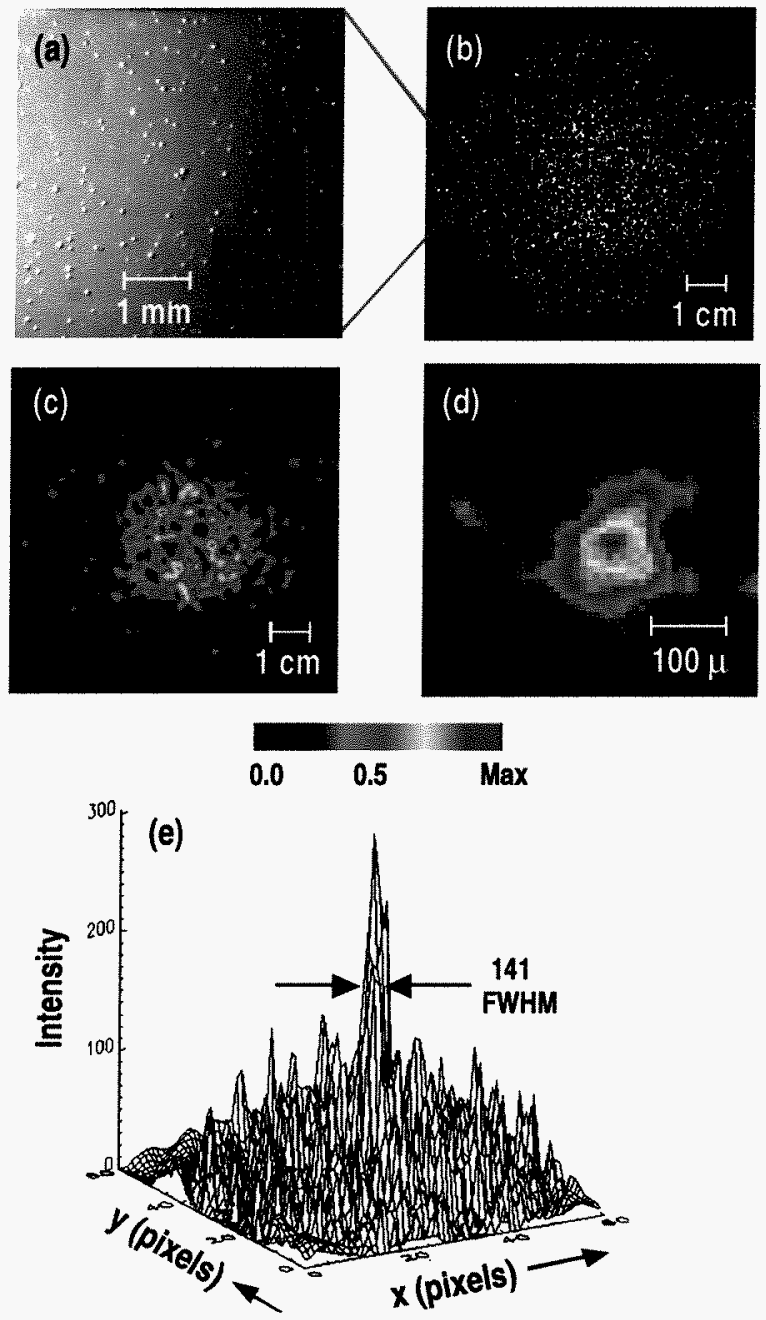

Fig. 1. Bubble detector images from a $6 \cdot 10^{13}$ yield OMEGA shot, including (a) microscope photograph of $60 \mu \mathrm{m}$ diameter bubbles in a single grid location, (b) $x-y$ plot of bubble locations, (c) coded false color image in detector plane, (d) and (e) unfolded neutron image in target plane. 